\title{
The Socio-Economic and Political Impacts of Youth Bulge: The Case of Sudan
}

\author{
Huda Mohamed Mukhtar Ahmed \\ Department of Econometrics and Social Statistics, University of Khartoum \\ P.O. Box 7879, Postal Code 11123, Khartoum, Sudan
}

Tel: 249-1227-26054. E-mail: haudashalaby@gmail.com, haudashalabi@hotmail.com

Received: March 25, 2014 Accepted: May 19, 2014 Published: June 6, 2014

doi:10.5296/jsss.v1i2.5769 URL: http://dx.doi.org/10.5296/jsss.v1i2.5769

\begin{abstract}
The present study investigates the impact of youth bulges on the armed conflicts in Sudan. It uses the 2008 census data on 25 states and builds a logistic regression model for the analysis. Relative risk analysis is also used to measure the association between the two variables. The impact of youth bulge on the armed conflict is not clearly detected, however, the impact of secondary school attendance rate for males and the access to clean drinking water is found to be statistically highly significant.
\end{abstract}

Keywords: Youth bulges, Sudan, Armed conflict, Youth unemployment 


\section{Introduction}

Youth bulge is a common phenomenon associated with the developing countries, especially those that achieved some success in reducing infant mortality but with still high fertility rates. Such countries have a history of rapid population growth and a high potential of future population growth with youth constituting the largest segment.

Globally, youth population aged 12-24 years is currently about 1.5 billion people, nearly $90 \%$ of them live in developing countries (World Bank, 2007). The increase of that category is known as youth bulge. The socio-economic and political impact of youth bulge is reflective, as it presents both opportunities and threats. It may be real assets if youth aspiration in getting quality education that meet labor market demand and then being absorbed in labor market are fulfilled; otherwise it may constitute serious social and political unrest to their countries.

The consequences of youth bulge thus depend on the policies and institutional environment of the hosting countries. In East Asia, for instance Bloom and Williamson (1998) concluded that the demographic transition has contributed positively to the East Asia economic miracle. However, similar demographic dynamics in Latin America failed to yield better economic outcomes (Fares \& Garcia, 2008).

In African countries the case is not better than that of Latin America; the consequences of youth bulges and widespread unemployment in these countries have been associated with insecurity, urban social unrest and political instability (Panday 2006; Urdal \& Hoelscher 2009; Frederiksen, 2010; Lintelo, 2011). For example, Klasen and Lawson (2007) in Uganda find out that the high population growth puts a considerable break on per capita growth and led to low achievements in households' poverty reduction. In Mozambique, however, the findings of a study on the impact of population dynamics on economic growth, revealed that population dynamics is not a major driver of a change in growth of per capita incomes, poverty or inequality (Klasen \& Woltermann, 2005). In Kenya, Okull, 2012 concluded in his paper that unless the youth challenges are addressed from an economic and demographic angle, the country will encounter more frequent labor unrest, political violence, urban displacement, environmental degradation and a rise in absolute poverty rates.

Several studies published by Urdal at the Peace Research Institute in Oslo, Norway, on youth bulges and conflict consistently show that other factors, such as low economic growth, economic hardship and levels of political participation pose greater conflict risks than youth bulges do (USAID 2007).

Sudan as many developing country is passing through the second stage of demographic transition, represented in declining child and infant mortality rates but with still high fertility rates. Those who are under the age of 25 and the young people aged 15- 24 represents $60 \%$ and $20 \%$ of the total population respectively. Most importantly, Sudan has a high potential of future population growth as the result of the transition of the huge masses (41\%) of age group $0-15$ over decades and the prevailing total fertility rate of 3.9 .

Sudan is also endowed with natural resources including oil, however, it suffers from several challenges; long civil wars, economic hardship, high youth unemployment, poverty, lack of basic infrastructure in large areas, and heavy reliance on subsistence agriculture. The long war in the south led to secession of southern Sudan and as a result, Sudan has lost a 
considerable portion of its resources. Conflicts are still going on in Southern Kordufan, Darfur, and the Blue Nile states.

Causes of armed conflicts are many, but the recent studies point to the youth bulge as an influential factor on the socio-economic and political instability of countries. Youth issues are put in the center of development policies in Sudan, however; they are rarely empirically well studied. The task of this paper is to shed light on the demographic transition and youth bulge to empirically examine their socio-economic and political impacts.

Understanding the risk and opportunities associated with youth bulges will enable the policy makers to design evidence-bases policies that address their needs and aspiration to reap the benefits of demographic dividend

\subsection{Objectives}

This paper aims to shed light on the demographic transitions taking place in Sudan and to examine the consequences of the resulting youth bulge on the political instability. This can be achieved through addressing the following specific objectives:

1). To examine the effect of youth bulges on political unrest.

2). To examine the effect of socio-economic variables on political unrest.

\subsection{Hypothesis}

$H_{01}$ : There is no association between the armed conflicts and youth bulges.

$H_{02}$ : There is no association between the armed conflicts and socio-economic variables

\subsection{Methodology}

The current paper adopts quantitative methods to build a model that examines the relationship between youth bulges and socio-economic change and political instability in Sudan. The model relies on secondary data combined from the Central Bureau of Statistics (CBS). The variables used in the analysis are: the onset of domestic armed conflict, percentage of population living below poverty line, economic growth rate, infant and under five mortality rates, literacy rates, youth unemployment rate, dependency ratio, proportion of population ages 15-24 to adult population, proportion of youth completed university education and number of ethnic groups. The data was stratified by states. The dependent variable is the onset of domestic armed conflict, a binary variable with 1 given to the states that experienced conflict within the last decade, 0 otherwise.

As the dependent variable is dichotomous, the appropriate statistical method for the analysis is logistic regression method.

The Logistic regression model best fit predicating a phenomenon such as group membership, from a set of predictors $\left(\mathrm{X}_{1}, \mathrm{X}_{2}, \ldots, \mathrm{Xn}\right)$. The dependent variable in logistic regression takes the value 1 with a probability of $\operatorname{success}(\phi)$, or the value 0 with probability of failure $(1-\phi)$.

Our logistic regression is expressed as follows:

$$
\operatorname{Logit}\{\Phi(Y)\}=\log \left[\frac{\phi(y)}{1-\phi(y)}\right]=\alpha+\beta_{1} X_{1}+\beta_{2} X_{2}+\beta_{3} X_{3}+\ldots+\beta_{9} X_{9}
$$


Where:

Y: denotes the onset of conflicts, 1 is given to states that ever witnessed armed conflicts and 0 otherwise. (state is sub-national level in Sudan)

$\mathrm{X}_{1}$ : proportion of population aged 15-24 of the total adult population

$\mathrm{X}_{2}$ : Access to clean drinking water

$\mathrm{X}_{3}$ : inaccessibility to sanitation facilities

$\mathrm{X}_{4}$ : Youth unemployment rate

$\mathrm{X}_{5}$ : Gross secondary school attendance rate for males

$\mathrm{X}_{6}$ : Dependency ratio

$\mathrm{X}_{7}$ : Number of ethnic groups.

$\mathrm{X}_{8}$ : Percentage of population living below poverty line

$\mathrm{X}_{9}$ : Literacy rates

\section{Population and the Economy in Sudan}

Increased population growth generally is viewed as a problem for any country; it means increased need for food, shelter, infrastructure, and services. In Sudan, the 2008 census counted 30.9 million people in the Republic of Sudan, a 21\% increase from the 1993 census. Sudanese population was counted at successive census as 10.3 million in 1955/56, 14.1 million in 1973, 21.5 million in 1983 and 25.6 in 1993 . The largest intercensal population growth $(52.5 \%)$ has taken place between 1973 and 1983(NPC, 2008).

During this period the crude death rate decreased from 21 to 17.2 and infant mortality rate decreased from 154 to 118 whereas the crude birth rate changed from 47.5 to 42.6 and total fertility rate changed from 6.8 to 6.5 . The percent change in crude birth rate and total fertility rate were by far much lower than the percent change in crude death rate and infant mortality rate. This relative decline in death rates compared to birth rates was the cause of the rapid population growth in the 1980s. Total decennial population growth declined sharply in the next decade following the 1980s peak and continued declining but in slow rate during the 2000s.

In terms of annual growth rates, The Republican Sudan's population growth rate (overall as well as natural) in 2008 was about $2.4 \%$, suggesting a doubling time of 29 years. Sudan population of 30.9 million in 2008 is anticipated to become 61.8 million by 2037 if current growth rate continues. A bout $20 \%$ of the total population is at age $15-24$ and about $42 \%$ are under 14 years of age, suggesting further population growth in the future.

Sudan is also endowed with rich natural resources and has the potential to become the major world's food basket. Annual economic growth rate averaged around 7\% during 1995 to 2004, representing twice the sub-Saharan Africa average - and amounted to $11.4 \%$ in 2006-2007 (IMF, 2008). However, this growth slowed to about 1.9\% in 2011 and 1.3 in 2012 (BoS, 2012), reflecting the stagnation of oil production, the global financial crisis as well as the local conflicts and the resultant huge cost of civil war.

Sudan has run into many armed conflicts with the southern part of the country for over half a century which was eventually culminated in secession of Southern Sudan. Moreover, conflicts in Darfur and recently in Kordufan and Blue Nile are still are going on. Rapid 
population growth and the resultant youth bulge coupled with economic hardship are among the factors that impede economic development and slow pace to achieve sustainable development.

\section{Theories and Empirical Works on Youth Bulges}

Thinking of demography as a tool of conflict analysis is hardly new. Previous studies of peace and conflicts reflected that inequalities that align with cultural, ethnic and religious characteristics proliferate civil wars and political instability (Haider, 2009), the recent studies argued that the root causes of political instability and civil wars are caused by demographic issues, such as youth bulge (Urdal, 2006) and this is supported by the actually happening events. For instance the 'springs revolutions' that have taken place in many regions of the Arab world have been driven by the youth population and in Africa, countries like Sierra Leone, Burundi and the DRC restless youth continuously threat peace and stability since they are continuously being used to fuel civil unrest as fresh recruits of militant and rebel groups (UNDP, 2011).

In the literature on internal instability, many hypotheses regarding the causes of different kinds of instability have been put forward. It has been argued that rapid economic growth immunizes regimes against pressures for change and thus rapid economic growth generates stability (Goldstone et al, 2005). Furthermore, economic stagnation is envisaged as a source of stability by some authors and as a source of instability by the others. Short-term economic crises or major depressions, nevertheless, are generally being alleged to increase the odds of political instability. Demographic factors - including a country's population size, population density, age distribution (the youth bulge), level or rate of urbanization, and ethnic composition (e.g. degree of fractionalization, or presence of certain-sized minorities) - have also been supposed as drivers of political instability (Goldstone et al., 2005)

Nazli Choucri is a pioneer in conducting empirical studies on the relation between youth bulge and armed conflicts; in 1974 she compared qualitative case studies of 45 local conflicts and found that in 10 conflicts, youth bulge had played a minor role but was not a vital cause in the initiation of those conflicts. The quantitative studies conducted by Collier in 2000 showed that increase in male cohorts increases marginally the likelihood of civil war.

Among the quantitative studies in this field is the one conducted by Urdal in 2002. The study found that youth bulges make countries more unstable in general and thus more susceptible to armed conflict. The research hypotheses are tested in an event history statistical model covering a high number of countries and politically dependent areas over the period 1950-2000. The study finds robust support for the hypothesis that youth bulges increase the risk of domestic armed conflict, especially under the conditions of economic stagnation. However, the model was criticized as being specific to certain regions and conditions and also in being unable to predict events such as the civil wars in the former Yugoslavia and the 2008 Russian invasion of Georgia-bloody conflicts that occurred during a low fertility period.

A new study that used case-control methods, to identify risk factors for political instability two years prior to event onset was conducted by Goldstone et.al in 2005. The models are able to identify states that will or will not experience political instability two years prior to event onset, 
with over $80 \%$ accuracy in the historical data across several random samples. The model examined a wide range of political upheavals and demonstrates that regime type is overwhelmingly the dominant factor behind revolutions, ethnic wars, and adverse regime changes. The study revealed that the effect of regime type is not a simple function of the degree of democracy or autocracy. Rather, certain kinds of autocracies and democracies are much more vulnerable than others, depending on the patterns of executive recruitment and political participation under those regimes

\section{Variables Description and Operationalization}

Since the analysis of youth bulge is region and condition specific; it becomes necessary to examine the relationship between youth bulge and armed conflicts for different countries. In Sudan, modeling the relationship between armed conflicts and socio-economic and demographic variables is hardly new and can help a lot in understanding the root causes of armed conflicts. The dependent variable used in the model is the onset of armed conflicts. Using the state as a unit of analysis, we gave the value 1 to the states that ever witnessed conflict onset and 0 otherwise.

The state is sub-national administrative level, and there are $15^{*}$ states in the Republic of Sudan. Though the southern states are no longer part of the Republic of Sudan after secession of South Sudan, still we included them in the study for the sake of modeling.

We justify the inclusion of the southern states because only 15 cases (states) with more than five variables, lead to misspecification of the model. Moreover, Southern Sudan was not only an important part of the series of armed conflicts in Sudan for half a century, but also the northern branch of Sudan People Liberation Movement is still fighting in Kordufan region.

We did not identify the time of conflicts or the number of episodes because in calculating the proportion of youth that is relevant to the specified time, we may need data on cohorts two decades before; which may not be available.

The second variable is youth bulge and for statistical purposes, The United Nations defines 'youth' as those persons between the ages of 15 and 24 years, without prejudice to other definitions by Member States (UN). According to Urdal, (2002), the operationalization that produces the most serious error is suggested by many prominent theorists; including Collier, 2000; Goldstone et al, 2010; Huntington, 1996) as they measured the size of youth cohorts (most commonly defined as those between 15 and 24 years) relative to the total population rather than to the adult population. As suggested by Urdal, countries with rapidly growing populations will tend to have under-estimated youth bulges because their under-15 populations are so large that inflates the total population.

In Sudan, as indicated before, about $42 \%$ of the total population is under 14 years of age and this will inflate the total population. In that, following the method behind Urdal, (2002), the study measures youth cohorts as 15-24 year-olds relative to the total adult population (15 years and above). Data on age distributions by state are obtained from the 2008 census data.

\section{Control Variables}

In our discussion on the theories of youth bulges and conflicts, we revealed that many economic and demographic variables may exacerbate armed conflicts. The present study chooses some of them as control variables. The selection of control variables was also 
restricted by the availability of data on them. For instance, data on poverty by state for Southern Sudan was not available; so we excluded it from the model and used some proxy variables such as proportion of population accessed clean drinking water and inaccessibly to sanitation facilities. Ensuring access to safe drinking water and sanitation is a crucial step to alleviate poverty. Access to safe water and sanitation facilities reduces the likelihood of catching diseases and lessens school absenteeism. Also women have time for income-generating activities instead of walking for long distance to collect water and hence reduce households' poverty (WASH, 2012). In sum, the inadequate supply of basic services increase the grievance of youth and accumulated grievance increases the likelihood of their being recruited in armed groups.

Ethnicity is a social segmentation that mostly induces violent conflict in the existence of youth bulges. Ethnicity is always synonyms to minorities; and minorities cause grievance and more likely to increase armed conflicts. Some empirical studies revealed that the existence of youth bulge fuel ethnic conflict (Huntington, 1996; Esty et al., 1998)

The present study used the total population of states as a proxy of the number of ethnic groups. It supposed that the larger the size of population the bigger the number of ethnic groups. The variable is represented as dummy and generated by weights as follows:

0 if ( $\mathrm{P}<1$ million), 1 if $(1 \mathrm{~m} \leq \mathrm{P}<2 \mathrm{~m}), 2$ if $(2 \mathrm{~m} \leq \mathrm{P}<3 \mathrm{~m}), 3$ if $(3 \mathrm{~m} \leq \mathrm{P}<4 \mathrm{~m}), 4$ if $(4 \mathrm{~m} \leq \mathrm{P}<5$ $\mathrm{m}), 5$ if $(5 \mathrm{~m} \leq \mathrm{P}<6 \mathrm{~m})$, where $\mathrm{P}$ is the total number of state population in millions.

The role of education as human capital is also important and should help in understanding the role of youth bulge in either economic development or political violence. Both Urdal and Hoelscher and Collier and Hoeffler have pointed to the fact that male secondary school enrollment is a significant variable in understanding youth bulge theories. Collier and Hoeffler argued that young males are the group from which rebels are most recruited, the number of years of secondary education affects earning potentials, and therefore having more years of schooling is likely to affect the opportunity cost of participating in conflict (Smith et al, 2012).

This study imposed two variables of education indicators in the model as control variables: literacy rate and gross secondary school attendance rate for males. The former indicates the social significance of education and the latter express the opportunity cost of joining armed groups. Both variables are calculated from the 2008 census data.

\section{Results}

The very important assumption for a logistic regression is independence across all observations. As indicated by the previous studies, in such analysis there is very likely that observations may not be independent of time and possibly of space. For the former, time was not imposed in the model, however, for the latter; it is difficult to defend because an armed conflict in one state may spread into another state to cause conflict there.

The effect of youth bulges on armed conflict propensity is tested with and without control variables. The study used the statistical package for social science SPSS (16) to analyze the data.

For model 1, (without control variables), the test of the full model versus a model with the intercept only was statistically significant, $\chi^{2}(1, \mathrm{~N}=25)=4.5$, P-value $=0.03$. The Hosmer 
and Lemeshow test was used to test the null hypothesis that there is a linear relationship between the predicator variables and the log odds of the dependent variable. An insignificant chi-square ( $P=0.258$, Table1), indicates that the data fit the model well; However, the effect of youth bulge on armed conflict is insignificant at 5\% level of significance, the p-value is 0.05 , Table (1).

Table 1. Risk of Armed Conflict by Youth Bulges in Sudan

\begin{tabular}{ccccc}
\hline \multirow{2}{*}{ Explanatory Variables } & \multicolumn{3}{c}{ Model 1 } & \multicolumn{2}{c}{ Model 2 } \\
\cline { 2 - 5 } & Without control variables & With control variables \\
\hline & S.E & Exp (B) & S.E & E (B) \\
Youth Bulge & 0.44 & 0.05 & 0.924 & 0.074 \\
Control Variables & $(0.232)$ & 1.56 & $(0.51)$ & 2.519 \\
GSSARm & & & & \\
Constant & -14.2 & 0.07 & 1.189 & 0.551 \\
N & $(7.8)$ & 0.1 & $(1.996)$ & 3.284 \\
-2 Log Likelihood & 25 & & 25 & \\
Pseudo R2 & 25.123 & $0.03 *$ & 15.13 & $0.00^{* *}$ \\
Hosmer \& Lemeshow & 0.238 & & $0.04)$ & \\
\hline
\end{tabular}

Source: Compiled by the author, GSSARm: Gross Secondary Schools Attendance Rate for Males.

The statistically significance of youth bulge is marginal and we assume it as insignificant; nevertheless, the model detected the direction of the relationship correctly. The positive sign of the coefficient together with the odds ratio suggest that an increase in youth bulge of one percentage point is associated with an increased likelihood of armed conflict of about $56 \%$.

For model 2 (with all control variables imposed in the model), the test of the full model versus a model with the intercept only is highly statistically significant, $\chi^{2}(2, \mathrm{~N}=25)=13.18$, $\mathrm{P}=0.00$. Also the Hosmer and Lemeshow is insignificant indicating that the data fit the model well (Table1). In model (2), youth bulge is also insignificant though the right sign is again detected.

Among the imposed control variables, the gross secondary school attendance rate for male is the only significant variable, with the p-value of 0.02 . The finding indicates that an increase of one percentage point in secondary school attendance rate for males decreases the likelihood of armed conflict by $92 \%$ (Table 1 ).

As the significance level of youth bulge is marginal with a P-value of 0.05 , we thought of further investigation. To do so, a new variable is calculated for youth bulge by assigning 0 to 
the states that include a youth proportion of less than or equal to 0.35 and 1 to the states that include a youth proportion of 0.36 or more. Relative risk analysis is conducted to measure the relationship between youth bulge and armed conflict. As indicated in Table 2, the relative risk of armed conflict is 12 time as high in the states with high proportion of youth to total adult population than in the states with low proportion of youth to total adult population. Moreover, the $95 \%$ confidence interval for the relative risk ratio does not include 1 , indicating that there is a significant difference in the occurrence of conflicts between state with high youth cohorts and states with low youth cohorts; and Cochran test is significant at $5 \%$ level of significance $(p$-value $=0.01)$ indicating that there may be some relationship between the armed conflicts and youth bulges.

Table 2. Relative risk of youth bulge and armed conflicts

\begin{tabular}{cccc}
\hline & \multirow{2}{*}{ Value } & \multicolumn{2}{c}{$95 \%$ Confidence interval } \\
\cline { 3 - 4 } & & Upper & Lower \\
\hline Odds ratio for war/ no war & 12 & 1.164 & 123.6 \\
Cohort youth more & 4.667 & 0.738 & 29.4 \\
Cohort youth few & 0.389 & 0.189 & 0.799 \\
$\mathrm{~N}$ & 25 & & \\
\hline
\end{tabular}

Source: Compiled by the author.

The relative risk analysis shows a significant relationship between youth bulge and armed conflicts; and the logistic regression model though the p-value is marginal at 5\% confidence level is significant at $10 \%$ level of significance. As a result we can accept what has been detected by the model; namely, that a percentage point increases in youth bulge may increase the likelihood of the onset of armed conflict by about $56 \%$. This result supports the hypothesis of the present study and the findings of the studies conducted by Urdal (2002) and UNDP (2011).

Model (2) also detected the negative relationship between the gross secondary school attendance rate for males and the armed conflict correctly (Table 1). According to the findings, one percentage point increase in the gross secondary school attendance rate for males may decrease the likelihood of armed conflict by around $92 \%$ and this is by far stronger than the effect of youth bulge. This result is consistent with our hypotheses and the previous work of Collier and Hoeffler (2002, 2004). Youth engaged in secondary education has a high opportunity cost of joining armed groups compared to those who are not engaged in secondary education.

All the other control variables were found to be insignificant. We thought of modeling poverty indicators in a separate model. We imposed three control variables; namely access to clean drinking water, inaccessibility to sanitation facilities and literacy rate. In model (3) in Table (3), the test of the full model versus a model with the intercept only was statistically significant, $\chi^{2}(1, \mathrm{~N}=25)=18.7, \mathrm{P}=0.00$. The Hosmer and Lemeshow test is 0.92 and access to clean drinking water is the only significant variable with the $p$-value $=0.02$. The findings suggests that an increase of one percentage point in the proportion accessed clean drinking 
water decreases the likelihood of armed conflict by around 7 percent.

Table 3. Risk of Armed Conflict by access to clean drinking water in Sudan

\begin{tabular}{lcc}
\hline \multirow{2}{*}{ Explanatory Variables } & \multicolumn{2}{c}{ Model 3} \\
\cline { 2 - 3 } & B & p-value \\
& S.E & Exp (B) \\
\hline Access to clean drinking water & -0.07 & 0.02 \\
& $(0.03)$ & 1.07 \\
Constant & -2.68 & 0.09 \\
& $(1.5)$ & 0.068 \\
N & 25 & \\
-2 Log Likelihood & 20.9 & $0.00 * *$ \\
Pseudo R & 0.43 & \\
Hosmer \& Lemeshow & 0.92 & \\
\hline
\end{tabular}

Source: Compiled by the author.

Poverty related variables were imposed in the model interchangeably with literacy rate and the best model was chosen. The negative sign of the estimated coefficient and the significance of the test are consistent with the hypotheses that poverty and political instability are related; lacking basic services such as clean drinking water creates grievance that is more likely to cause conflicts.

Some reasons are suspected to be behind the failure of the model in predicting the significance of youth bulge at 5\% level of significance i.e. the p-value being marginal. One of these reasons is that the sample size is small, despite the inclusion of the 10 states of Southern Sudan. We used 25 cases and this limited our ability in imposing large number of variables because for more parameters we need more cases. In addition to that we failed to get some indicators for Southern Sudan. The second reason is that the initial assumption of the logistic regression, namely the independence of space was not manipulated and it is most probable that there is space dependence because war easily spread from state to state especially in the existence of youth bulge. However, if we had changed the confidence interval to $90 \%$, the entire variables would have been statistically significant.

\section{Conclusion}

Sudan is endowed with rich natural and human resources; however it suffers many political and economic challenges. The most important political challenge that also feeds the economic problems is the long lasing civil wars. The root causes of these wars are many, including political, social and economical issues; however, some recent studies argue that demographics are among the causes of political instability globally. The present study aimed to verify this argument in the case of Sudan.

The present study used logistic regression model to investigate the relationship between youth bulges and armed conflicts in Sudan. Many socio-economic variables are also used as control variables in the model. Three models were built; two examined the relationship of youth bulge and armed conflicts. Proportion of youth was imposed with and without control variables and 
in both of them youth bulge was significant only at $10 \%$ level of significance, however, the appropriate sign was detected by the models. Risk analysis also was conducted and it ensures the existence of some relationship between youth bulge and armed conflicts. Other factors such as gross secondary schools attendance rate for males and access to clean drinking water are also found to be related to armed conflicts in Sudan.

The study recommends the reinvestigation of the political impacts of youth bulge through building a rigorous model using more appropriate data such as the census raw data. This will help in clearly understanding the demographic impacts of political instability. Moreover, as the study evidently detected the existence of a relationship between secondary education for males and poverty indicators and armed conflict; any policy to stop armed conflicts has to address education and provision of basic social services.

\section{Acknowledgement}

The author would like to thank all the anonymous referees of this reputable journal for their invaluably helpful comments and suggestions.

\section{References}

Bloom, D. E., \& Williamson, J. G. (1998). Demographic Transitions and Economic Miracles in Emerging Asia. World Bank Economic Review, World Bank Group, 12(3), 419-55. Retrieved from http://www.nber.org/papers/w 6268

Frederiksen, B. F. (2010). Mungiki, Vernacular Organization and Political Society in Kenya. Development and Change, 41, 1065-1089. http://dx.doi.org/10.1111/j.1467-7660.2010.01670.x

Goldstone, J. A., Bates, R. H., Epstein, D. L., Gurr, T. R., Lustik, M. B., Marshall, M. G., ... Woodward, M. (2010). A Global Model for Forecasting Political Instability. American Journal of Political Science, 54, 190-208. http://dx.doi.org/10.1111/j.1540-5907.2009.00426.x

IMF. (2008). Sudan: First Review of Performance Under the 2007-08 Staff-Monitored Programme.s.1. : International Monetary Fund, June 2008.

Klasen, S., \& Woltermann, S. (2005). The impact of demographic dynamics on economic development, poverty and inequality in Mozambique, Diskussionsbeiträge aus dem Volkswirtschaftlichen Seminar der Universität Göttingen, No. 126. Retrieved from http://hdl.handle.net/10419/31962

Lintelo, D. (2011). Youth and policy processes, FAC Working Paper 25, Brighton: Future Agricultures Consortium. Retrieved from www.future-agricultures.org

Nazli, C. (1974). Population Dynamics and International Violence: Propositions, Insights and Evidence. Lexington, Mass.: D.C. Heath/Lexington Books.

Okull, P. (2012). Demographic Transition and the Youth Bulge- the case of Kenya.

Panday, S. (2006). African Youth Charter. HSRC Review, 4(3).

Smith, A., \& Smith, E. C. (2012). Youth, Education, and Peace building. Retrieved from http://www.unescocentre.ulster.ac.uk/\#\&panel2-2

URDAL, H. (2006). A Clash of Generations? Youth Bulges and Political Violence. International Studies Quarterly, 607-629. http://dx.doi.org/10.1111/j.1468-2478.2006.00416.x 


\section{Macrothink}

Journal of Social Science Studies

ISSN 2329-9150

2014, Vol. 1, No. 2

Urdal, H., \& Hoelscher, K. (2009). Urban youth bulges and social disorder - an empirical study of Asian and sub-Saharan African cities. Policy Research Working Paper, World Bank. $5110,26$.

USAID. (2007). Youth and Conflict Supplement. Washington: USAID.

World Bank. (2007). World Development Report 2007: Development and the Next Generation Washington D.C, World Bank.

WASH United, Freshwater Action Network (FAN Global), Water Lex. (2012). The human right to safe drinking water and sanitation in law and policy - a sourcebook.

UNDP. (2011). Youth and Employment in Sudan. A Consolidated Report Labor Market Survey Findings From Three Northern States Blue Nile, North Kordufan, South Kordufan States.

Note 1: Proxy of poverty (access to safe drinking water and inaccessibility of sanitation facilities) are used in the model interchangeably and so the gross secondary schools attendance rate and literacy rate, then we chose the best model.

\section{Copyright Disclaimer}

Copyright reserved by the author(s).

This article is an open-access article distributed under the terms and conditions of the Creative Commons Attribution license (http://creativecommons.org/licenses/by/3.0/). 